\title{
THE STAINING REACTIONS OF CHORDOMA
}

\author{
BY \\ T. CRAWFORD \\ From the Department of Pathology, St. George's Hospital Medical School, London
}

(RECEIVED FOR PUBLICATION OCTOBER 10, 1957)

Although chordoma is a rare tumour well over 300 cases have been reported, and the excellent published descriptions of both pathological and clinical features leave little to be added (Stewart, 1922 ; Cappell, 1928 ; Mabrey, 1935 ; Dahlin and MacCarty, 1952). The pathological diagnosis depends on the recognition of the physaliphorous or "bubble-bearing" cells which are the most striking feature of the histological picture. These cells (Fig. 1) often attain great size and usually occur in groups or cords with an epithelial pattern; they are distinguished by the presence of numerous clear vacuoles of varying size which are separated by faintly eosinophil cytoplasm, the cell having almost an aerated appearance. The groups of cells are separated by a matrix or ground substance which has a similar frothy vacuolated appearance to the cell cytoplasm. In some areas -mainly the older parts of the tumour-the cells collapse to nondescript stellate and fusiform varieties and are often separated quite widely by this frothy ground substance (Fig. 2). Biopsy from such an area presents considerable difficulty and has often led to an erroneous diagnosis of chondrosarcoma, especially when the tumour occurs in one of the less common sites such as a spinal vertebral body. In these circumstances some staining reaction which would distinguish between the ground substance of cartilage (more particularly neoplastic cartilage) and chordoma would be invaluable. The present paper presents from this point of view a study of material from six cases of chordoma.

\section{Material and Methods}

Some details of the six cases from which the pathological material was obtained are given in Table I. These cases presented the usual features of patients with chordoma, though Case 1 came into the rare group in which blood-borne metastases develop, while in Case 2 the tumour involved the upper dorsal vertebrae, which are the least frequently affected parts of the spine-indeed Chiasserini and Marchiafava (1956) were able to find reports of only 10 cases with this localization.
TABLE I CLINICAL SUMMARIES OF CASES STUDIED

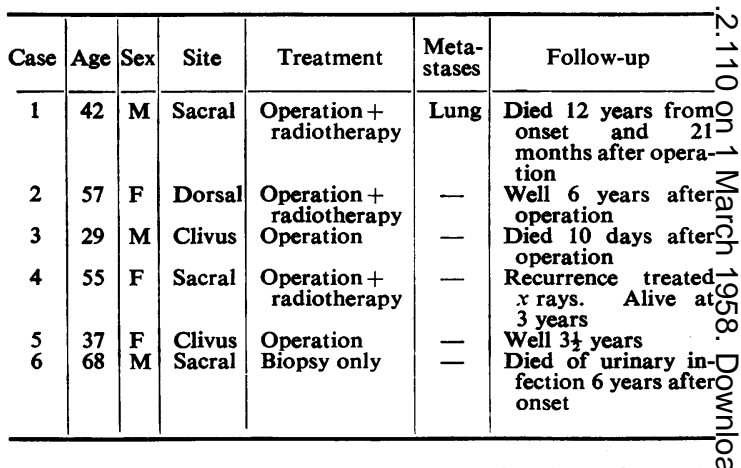

Material from all the cases was fixed in formolsaline and embedded in paraffin, and in addition $\odot$ frozen sections were cut from formalin-fixed blocks $\overrightarrow{\vec{F}}$ from Cases 1, 3, and 4 for sudan staining. The stain-응 ing methods employed were Ehrlich's haematoxylin and eosin, van Gieson's method, Mallory's phospho=tungstic-acid-haematoxylin, the picro-Mallory method:(Lendrum and McFarlane, 1940), the reticulin stain of Gordon and Sweets (1936), Best's carmine, and South-igate's mucicarmine. For the special histochemical 3 . procedures, including the methylene blue extinctioni test, the methods recommended by Pearse (1953) were $\frac{\mathrm{O}}{3}$ followed. For the methylene blue extinction tests a veronal-acetate buffer was used and the $p \mathrm{H}$ of eachs tube was checked with a glass electrode $p \mathrm{H}$ meter.

The chance occurrence of pulmonary metastases in Case 1 enabled a direct comparison, in the same sec $\bar{N}$ tions, between the reactions of normal bronchial car-os tilage and the chordomatous metastases (Fig. 3). AN parallel series of preparations from a block showing pulmonary metastases of a chondrosarcoma of femufu allowed the comparison to be extended to neoplastic cartilage.

\section{Results}

The cytoplasm of cartilage and chordoma cells ${ }^{\infty}$ frequently contains glycogen, giving a positive reaction with Best's carmine and staining strongly with the periodic-acid-Schiff (P.A.S.) technique? These reactions are dispelled by pre-treatment oB the sections with diastase, but remain after treat? ment with hyaluronidase. 


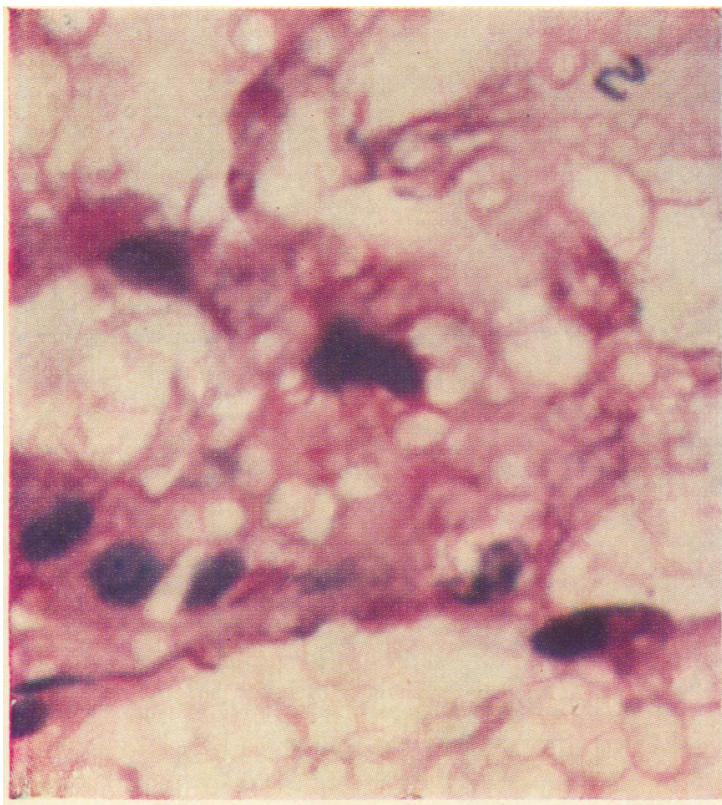

FIG. 1

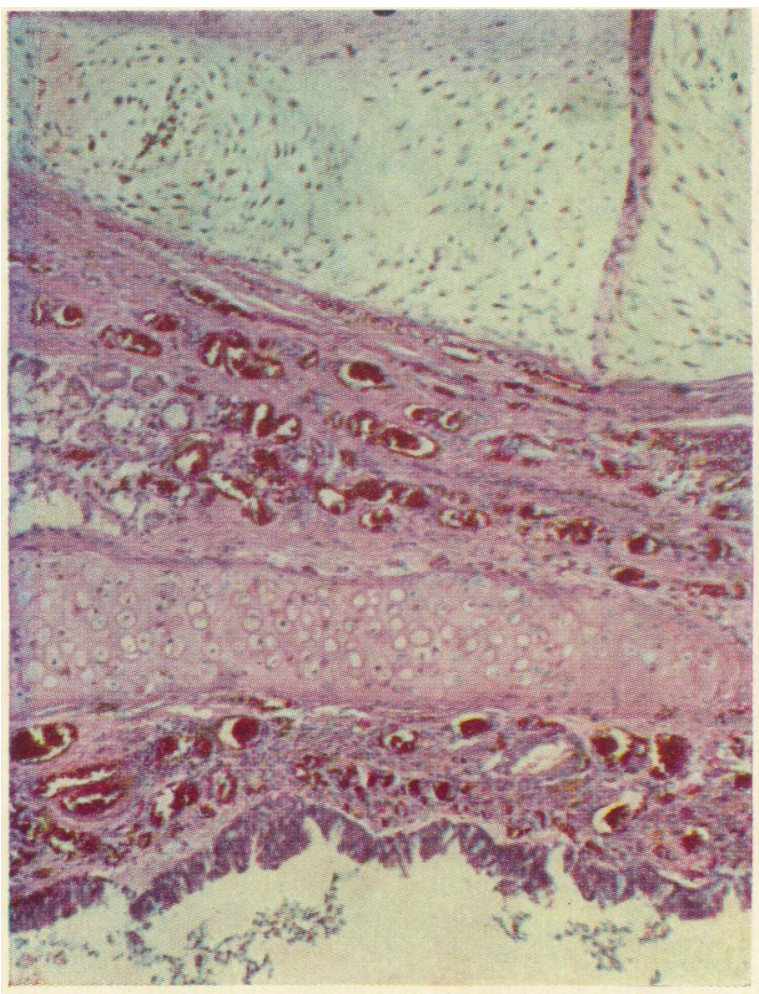

FIG. 3

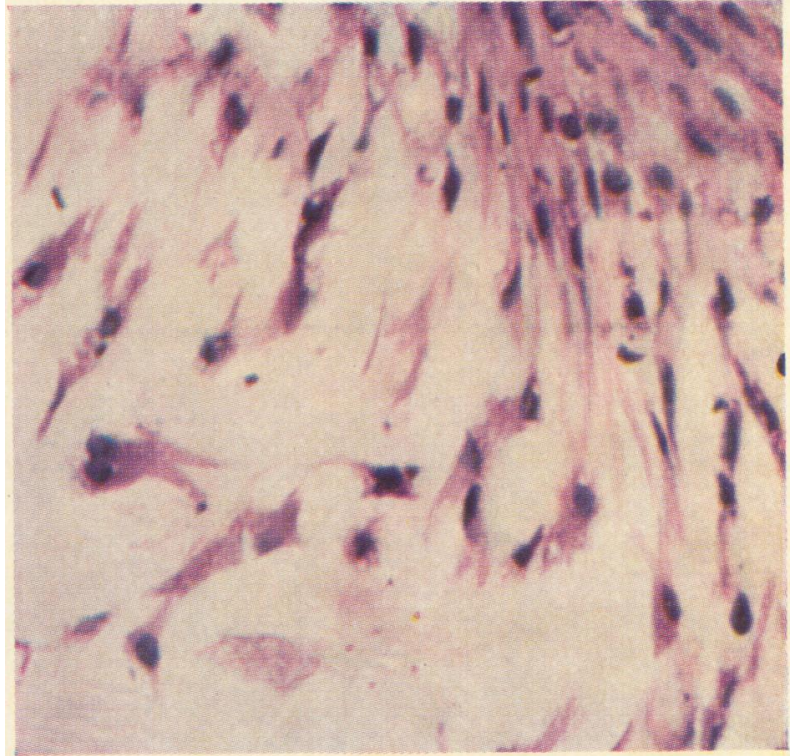

Fig. 2 .

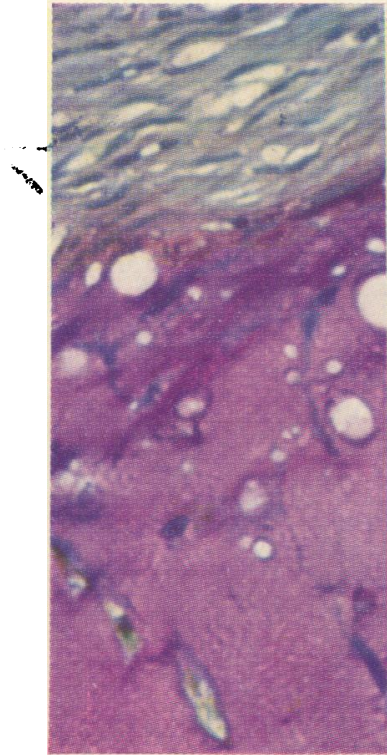

(a)

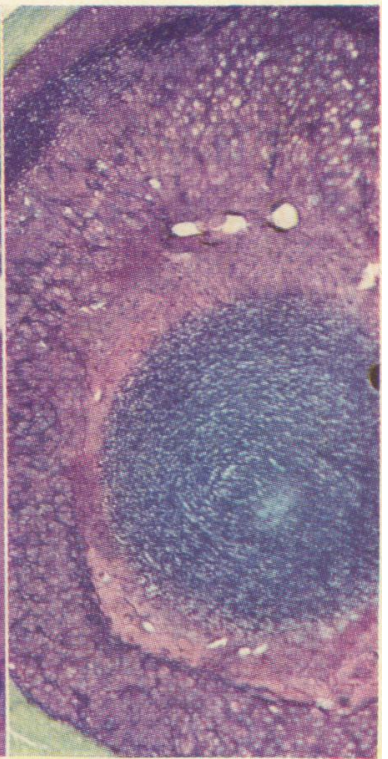

(b)
FIG. 4

FIG. 1.-Physaliphorous cells and vacuolated matrix. P.A.S., $\times 500$.

Fig. 2.-Stellate and fusiform cells in abundant pale-staining ground substance. P.A.S., $\times 250$.

FIG. 3.-Section of lung from Case 1 enabling direct comparison between staining reactions of bronchial cartilage below and chordomatous metastasis above. Haematoxylin and eosin, $\times 45$.

FIG. 4.-Metachromatic reaction with toluidine blue. (a) Chordomatous metastasis, $\times 200 ;(b)$ chondro-sarcomatous metastasis with neoplastic cartilage, $\times 50$. 


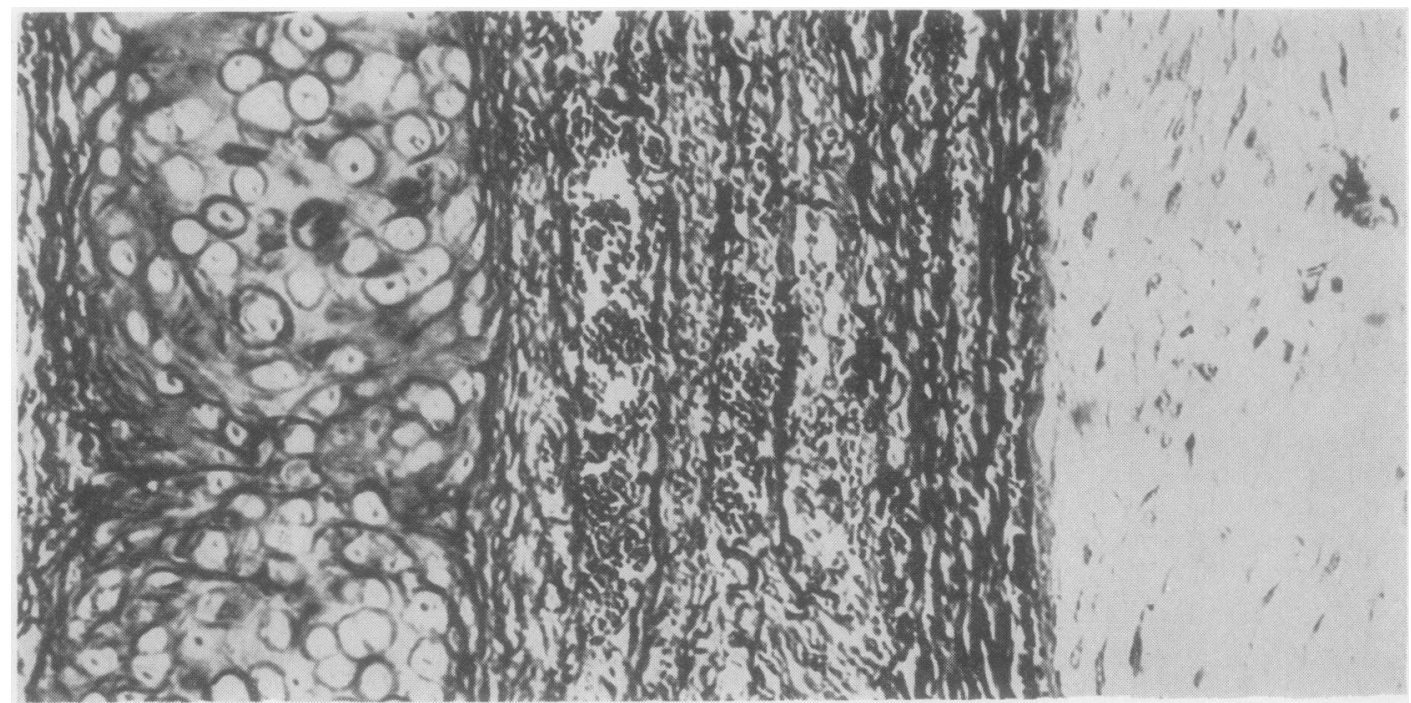

FIG. 5.-Section of lung from Case 1 showing bronchial cartilage to the left and chordomatous metastasis to the right. Reticulin stain, $\times 150$.

The staining reactions of the ground substances of the two tissues are summarized in Table II. The positive Millon reaction given by both tissues merely indicates the presence of tyrosine-containing proteins. The P.A.S. staining given by both tissues (though usually stronger with cartilage than with chordoma) is of the type associated with mucins of connective tissue origin, rather than the more brilliant staining of the mucins of epithelial origin. The character of this staining is unchanged when the sections are previously treated with diastase or hyaluronidase. Chordomatous ground substance gives a more strongly metachromatic reaction with toluidine blue than does normal bronchial cartilage, but the neoplastic cartilage also gives a strong reaction (Fig. 4). Both tissues give similar positive staining with mucicarmine and with alcian blue. The methylene blue extinction test, with both tissues, gives a value between $p \mathrm{H} 3$ and $p \mathrm{H} 2$.

Turning to the more orthodox and empirical staining procedures listed in the lower part of

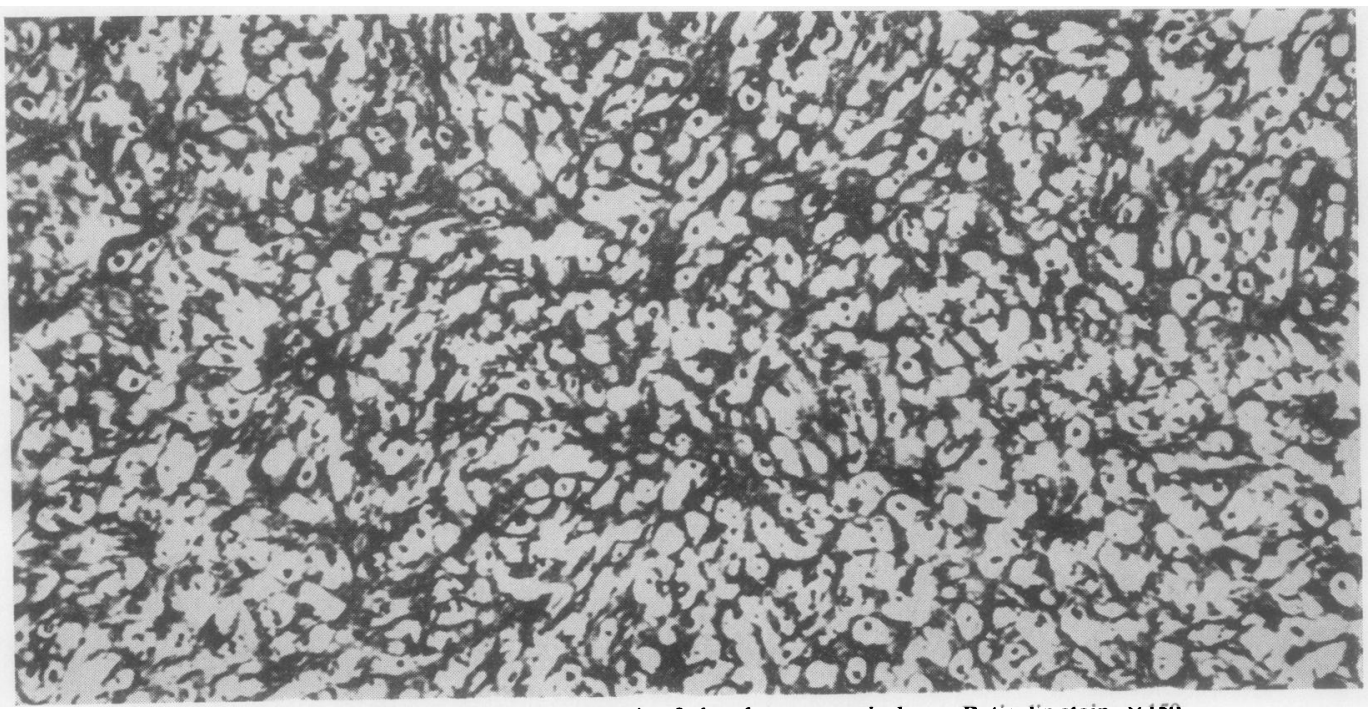

FIG. 6. - Neoplastic cartilage from metastasis of chondrosarcoma in lung. Reticulin stain, $\times 150$. 
TABLE II

STAINING REACTIONS OF GROUND SUBSTANCE OF CARTILAGE AND CHORDOMA TISSUE

\begin{tabular}{|c|c|c|c|}
\hline Method & & Chordoma & Cartilage \\
\hline 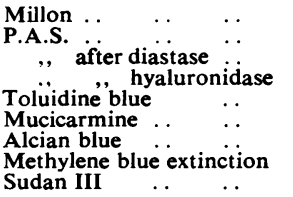 & $\begin{array}{l}\cdots \\
\cdots \\
\cdots \\
\cdots \\
\cdots \\
\cdots \\
\cdots\end{array}$ & $\begin{array}{l}\text { Positive } \\
\text { Faint pink } \\
\text { Unchanged } \\
\text { Metachromatic } \\
\text { Positive } \\
\text { pH'3-2 } \\
\text { Negative }\end{array}$ & $\begin{array}{l}\text { Positive } \\
\text { Pink } \\
\text { Unchanged } \\
\text { Metachromatic } \\
\text { Positive } \\
\text { pH'3-2 } \\
\text { Negative }\end{array}$ \\
\hline $\begin{array}{l}\text { Haematoxylin and eosin } \\
\text { van Gieson } \ldots \\
\text { Picro-Mallory . . } \\
\text { Phosphotungstic-acid- } \\
\text { haematoxylin } \\
\text { Reticulin (Gordon and Sweet }\end{array}$ & $\begin{array}{l}\cdots \\
\cdots \\
\text { ets) }\end{array}$ & $\begin{array}{l}\text { Almost unstained } \\
\text { Blue", , } \\
\text { Unstained }\end{array}$ & $\begin{array}{l}\text { Variable } \\
\text { Pink } \\
\text { Deep blue } \\
\text { Brownish pink } \\
\text { Diffuse staining }\end{array}$ \\
\hline
\end{tabular}

Table II, it is interesting to find that these provide a better differentiation between the two substances than do the supposedly more precise methods above. With all these empirical techniques chordomatous matrix stains feebly or not at all whereas the cartilaginous ground substance gives reactions approaching more nearly those of collagen fibres. Perhaps the most clear-cut distinction is obtained with the reticulin stain. This gives quite heavy deposition in both normal and neoplastic cartilage, sharply outlining the cells and precipitating more diffusely in the intervening ground substance. The chordomatous tissue, on the other hand, remains completely unstained (Figs. 5 and 6).

\section{Discussion}

The histochemical reactions recorded lead to the conclusion that the reacting substances in both cartilage and chordoma fall into the category of acid-mucopolysaccharide - a conclusion in agreement with that arrived at by Iurato and Leonardelli (1956) from study of three examples of rhinopharyngeal chordoma. It is of particular interest that these two substances, produced as they are by tissues of such widely different embryological origin and separated so widely in their phylogenetic history, should resemble one another so closely in their histochemical reactions. The significance of this observation is obscure, but it might perhaps provoke speculation on the influence of function on structure even at the chemical level.

From the diagnostic point of view, these histochemical reactions are of little assistance. The diagnosis of chordoma depends essentially on the recognition of physaliphorous cells lying in a mucinous matrix - features which may be more distinctive in a P.A.S.- or toluidine-blue-stained section than in a routine haematoxylin-and-eosin preparation. The absence of staining of the ground substance with phosphotungstic-acidhaematoxylin and with the reticulin method may, however, provide a useful pointer when typical physaliphorous cells are absent from the section.

\section{Summary}

Material from six cases of chordoma, one of which had pulmonary metastases, has been studied. The staining reactions have been compared with those of normal and neoplastic cartilage. The mucin stains give the reactions of acid-mucopolysaccharide with both cartilaginous and chordomatous ground substance, and the two tissues cannot be clearly distinguished by these means. The sharpest histological distinction is achieved by the phosphotungstic-acid-haematoxylin and the reticulin stains. With both these techniques chordomatous matrix remains unstained while cartilaginous ground substance is quite strongly impregnated.

I am indebted to Dr. A. D. Morgan, of the Westminster Hospital, for providing me with material from the necropsy on Case 1.

This investigation was supported by a grant to St. George's Hospital Medical School from the British Empire Cancer Campaign.

\section{REFERENCES}

Cappell, D. F. (1928). J. Path. Bact., 31, 797.

Chiasserini, A., Jr., and Marchiafava, G. (1956). Policlinico, Sez.prat., 63,1022 .

Dahlin, D. C., and MacCarty, C. S. (1952). Cancer, 5, 1170.

Gordon, H., and Sweets, H. H. (1936). Amer. J. Path., 12, 545.

Iurato, S., and Leonardelli, G. B. (1956). Tumori, 42, 559.

Lendrum, A. C., and McFarlane, D. (1940). J. Path. Bact., 50, 381. Mabrey, R. E. (1935). Amer. J. Cancer, 25, $50 \mathrm{i}$. Pearse, A. G. E. (1953). Histochemistry, Theoretical and Applied,
pp. 414-440. Churchill, London.

Stewart, M. J. (1922). J. Path. Bact., 25, 40. 